\title{
CROSS-CULTURALISM AND THE APPLICATION OF LEADERSHIP EDUCATION IN MAINLAND CHINA
}

\section{Abstract}

The internationalization of United States higher education has been described as a "two-way street" where students arrive at knowledge transfer. That transfer occurs through a curriculum deemed "unidirectional" with no relevance to local issues or needs and results in limited application and educational colonialism perceptions. Specific to leadership education, the extant literature presents implications of neglect to cultural contexts traditionally reflected in the curriculum within a host nation. We used an explanatory mixed methods design for this study to investigate the degree to which undergraduate Western-based leadership studies courses taught in China reflect the notion of "neocolonialism" by prioritizing Western interests and values.

While the study's quantitative results reveal cultural differences in leadership education concepts, the qualitative follow-up phase finds students' appreciation in the utility of leadership concepts and knowledge gained from the leadership curriculum. Students could cite specific situations in which they employed leadership concepts acquired from their respective leadership courses.

\section{Background of the Study}

The internationalization of United States higher education has been described as a "two-way street" where students arrive at the transfer of knowledge (Altbach \& Knight, 2007: 291). The curriculum that facilitates that transfer has been deemed "unidirectional," with no relevance to local issues or needs (Nguyen, Elliott, Terlouw, \& Pilot, 2009), resulting in a limited application or unwanted perceptions of educational colonialism (Altbach, 2003). The current study will investigate the degree to which undergraduate Western-based leadership studies courses taught in China may reflect the notion of being "elitist," described by Crossley and Tikly (2004) as "lacking relevance to local realities and are often at variance with indigenous knowledge systems, values, and beliefs" (p. 149).

\section{Purpose of the Study}

The purpose of this study is to examine the degree of impact and transferability of Western-centered leadership education against Eastern-centered notions and practices of leadership. Chinese students' perceived difficulty of synthesizing leadership theory in university-level coursework is the impetus for this investigation. While issues involving cross-culturalism, 
the applicability of curriculum, and the salience of leadership education were all concerns, our primary question was whether, because of a perceived difficulty in grasping leadership principles, instructors engaged in neocolonialist pedagogy. Neocolonialism reflects the interests of Western nations and, more broadly, Western capitalism, according to Tiky (2004). However, it is considered a form of "new imperialism" that recognizes the colonized nation's sovereignty. We wondered if the difficulty in the knowledge transfer and retention our students were experiencing was due to concepts so foreign to our students that they may not fully appreciate and use leadership education.

\section{Literature Review}

To prepare for a study examining the possible tension between Western concepts of leadership and their applicability globally, a review of the literature establishes the justification for such research. While the current body of literature adequately addresses the internationalization of United States higher education, there appears to be a noticeable absence of research on the cultural nuances of Western leadership thought and approaches to leadership education that may have implications on its utility in Asia. This study examines contemporary notions of Western pedagogy in contrast to Confucian pedagogy as a way to understand the effects of the crosscultural transfer of knowledge. We also define and differentiate critical pedagogy and culturally relevant teaching as they interconnect with the east-west pedagogical dyad. We argue that successful and culturally conscious leadership instructors practice all of these pedagogies in varying degrees.

Western Pedagogy. We regard the emergence of Western pedagogy as a derivative of the Socratic
Method. Dialogue between student and teacher marks this teaching method by asking questions to spark critical thinking and drawing out ideas by posing questions that test underlying assumptions and logic. The Socratic Method holds that the student cannot come away with knowledge by being taught or told. The "respondent" already has the knowledge; they are just having trouble "getting ahold of it" (Seeskin, 1987, p. 5). Spring (2008) asserts that Western pedagogies emphasize teachers' professionalism, autonomy, student-centered learning, active learning, and equity promotion.

Critical Pedagogy. Critical pedagogy asserts that teaching is a political act because some students are possibly favored over others. It also examines the power instructors hold and its implications. It is similar to Western pedagogy in that it seeks to empower students to become active and engaged in the classroom and beyond. It is similar to Western pedagogy in that it challenges students to question assumed knowledge and understandings. Instructors use their authority to support students (Kincheloe, 2008).

Culturally Relevant Teaching. This form of teaching uses various instruction methods to tailor learning to aspects of the students' culture. Culturally relevant teaching tries to establish the conditions for equitable educational outcomes for all students. It tries to address gaps in academic achievement, in our case, between Chinese and Western-situated students. It acknowledges that gaps between these two groups may exist because of student/teacher language gaps or differences in cost/benefit perceptions of education (Equity Alliance, 2011)

Confucian Pedagogy. Confucian pedagogy holds 
that the instructor has the responsibility to provide oral and written instruction to the students. Classroom instruction consists of instructional monologue rather than a dialogic exchange in the classroom. Wu and Tarc (2016) posit that traditional approaches such as teachers' use of their authority to keep order in class may still be necessary because Chinese students are accustomed to instructors' role as parents or managers (p. 69).

Among others, what follows are those that are still of great relevance to today's school practice in East Asian countries:

- The practice of the Rite ( $\mathrm{Li}$ 禮) that is often confounded with 'formalities' but is a sort of body-knowledge;

- The method of memorization that is often seen as 'rote learning' but can have a deeper significance as a method of learning;

- The conformity to norms and authority as a method of self-discipline;

- The broader understanding of the self that goes beyond the individual self of the modern West (Kwak, Kato \& Hung, 2016)

Our best understanding of the Rite ( $\mathrm{Li}$ 禮) is that it refers to the Confucian practice of making what was previously invisible visible through "textual learning" and "bodily practices" (Feuchtwang, 2016). It involves a spiritual interaction between humans, nature, and material objects.

Leadership Literature in the Classroom. This section discusses the connection our students have with Western leadership concepts and how they apply theoretically, personally, professionally, and civically. Our leadership studies program in China offers B.S. or B.A. degrees in organizational leadership. We believe that the concepts learned during the students' course of study will help them understand how leadership advances organizational change, increases organizational performance and profitability, and enhances personal and professional development. The leadership theories underpinning our classes are rooted in extant literature and consist of a wide array of concepts typical of those found in the U.S. When teaching leadership to our Chinese students, we attach situatedness, theory, and practice to desired outcomes and authentic leadership behavior.

Theoretical Connectedness. We start with an interdisciplinary course designed to introduce and connect students to the "nature" of leadership. As stated in the syllabus, "Students gain a broad understanding of leadership's history and origins, theoretical approaches to leadership, and the essence of contemporary leadership." We immerse and orient our students in leadership thinking and take them through the eras of leadership evolution. We weave these associated theories throughout the entire program.

\section{Early Trait Theories.}

- Great Man Theory

- Trait Theory, Stogdill $(1948,1974)$.

\section{Charismatic Theory.}

- House (1977)

- Conger and Kanungo (1998)

\section{Contemporary Trait Theories.}

- Stephen Covey (1991) "principlecentered leaders." 7 Habits of Highly Effective People

- Goleman (2005) Emotional Intelligence

Behavioral Theories.

- Lewin, Lippitt, and White (1939) autocratic, democratic, and laissez-faire

- McGregor (1960) Theory X and Theory Y

\section{Contingency and Situational Theories.}

- Fiedler (1967) LPC model 
- Path-Goal Theory, House (1971)

- Hersey and Blanchard

Situational Leadership Theory

Power and Influence Theories.

- French and Raven (1959) identified social power sources

- Social Exchange Theory, Homans (1958)

\section{Transformational and Transactional Leadership Theories.}

- Burns (1978) Transformational Leadership

- Bass (1985) Transactional Leadership

Professional Connectedness. Subsequent classes introduce the students to the tasks, strategies, and skills of effective leadership behavior and practice, including course activities that move them from theory to leadership processes. Course concepts include successful collaboration, team-building, and effective change-making organizationally, societally, and globally.

\section{Symbolic Leadership Theory.}

- Symbolic leadership (Bennis \& Nanus, 1985)

- Social change leadership

- Distributed Leadership.

- Or shared leadership Gardner (1990)

Personal Developmental Connectedness. These leadership theories and practices illuminate the leadership discipline's internal cognitive processes and focus on authenticity in leadership behavior. They help our students understand the difference between authoritarian leadership and the informal aspect of leadership theory and self-empowerment.
Risk Leadership.

- Lower-level employees confront and challenge authority as a means of transforming their organization (Crawford, Brungardt, \& Maughan, 2005).

\section{Followership.}

- $\quad$ Rost (1995)

- Servant Leadership.

- Greenleaf (1977)

- $\quad$ Ethical Leadership.

- Ciulla (2014)

- Emotional Intelligence.

- Goleman (2005) E.Q.

- Chestnut (2017) the Enneagram

Internationalization of United States Higher Education. Higher education has been credited as one of the United States' greatest exports, adding to the economic and social prosperity of the communities of which they are a part (Moulakis, 2011; Pavoncello, 2015). The current body of literature presents research and commentary on the various manifestations of United States education in foreign countries, including international branch campuses, partnerships, and foreign universities maintaining regional accreditation status in the United States (Altbach, 2003; Blanco-Ramirez 2013; Bourgeois, 2017; Lane \& Kinser, 2013). As stated earlier, the literature also contains indictments of an empiricist approach by U.S. higher education institutions, consisting of educational colonialism (Altbach, 2003) and neocolonialist implications (Nguyen et al., 2009)educational policy makers in non-western countries tend to look to the west. Thus they may 'borrow' policies and practices that were originally developed and operated, and which appeared to be effective, in a very different cultural context to that of their own societies. In effecting such transfer, detailed consideration of particular aspects of the culture and heritage of the originating country is 
often neglected. To illustrate some of the problems that result from this, the article presents a case study of the application of Cooperative Learning, an educational method developed in the west, within an Asian context. Drawing upon Trompenaars and Hampden-Turner's typology of seven cultural dimensions, our examination of western method and eastern context reveals a complex web of cultural conflicts and mismatches. The paper concludes by suggesting that non-western cultures should seek to reconstruct imported pedagogic practices in accordance with their own world views and in line with their own norms and values.", "author" : [ \{ "dropping-particle" : "', "family" : "Nguyen", "given" : "Phuong Mai", "non-dropping-particle" : "', "parsenames" : false, "suffix" : "' \}, \{ "dropping-particle" : "', "family" : "Elliott", "given" : "Julian G.", "non-droppingparticle" : "', "parse-names" : false, "suffix" : "" \}, \{ "dropping-particle" : "', "family" : "Terlouw", "given" : "Cees", "non-dropping-particle" : "', "parse-names" : false, "suffix" : "' \}, \{ "dropping-particle" : "', "family" : "Pilot", "given" : "Albert", "non-dropping-particle" : "', "parse-names" : false, "suffix" : "' \} ], "container-title" : "Comparative Education", "id" : "ITEM-1", "issue" : "1", "issued" : \{ "date-parts" : [ [ "2009" ] ] \}, "page" : "109-130", "title" : "Neocolonialism in education: Cooperative Learning in an Asian context", "type" : "article-journal", "volume" : "45" \}, "uris" : [ "http:// www. mendeley.com/documents/?uuid=1 fa89254827b-4734-ab34-47f0288c5e1e" ] \} ], "mendeley" : \{ "formattedCitation" : "(Nguyen et al., 2009. Traditionally, important cultural contexts are reflected in educational institutions' curriculum explicitly and in less overt ways (Wong, 2001). However, Altbach (2003) and Nguyen et al. (2009) argue overpowering neglect for the cultural context in the societies and communities in which U.S. institutions establish a presence. Relative to leadership education, similar sentiments have echoed this idea, insisting that "curricula are based largely on a Western business knowledge base developed for twentieth-century business assumptions, and virtually ignore the leadership wisdom and knowledge found in other societies" (Turnbull, 2011, p. 172).
Cultural Difference. The differences in Western (primarily the United States) and Chinese cultures are well documented. Considering cultural factors such as power distance, relationship orientation, and gender roles, the contrast between the two cultures approaches near polarity. The GLOBE study examines the differences between 62 different cultures. It measures China as very low in metrics like gender egalitarianism, assertiveness, future orientation, and humane orientation (Javidan, House, \& Dorfman, 2004). Conversely, this same study found that Western cultures, like that of the United States, value these cultural components much higher. These elements of culture influence concepts of leadership and leader behaviors. An informed awareness of and ability to navigate cultural differences increases a leader's likelihood to succeed (Crowne, 2008; Lovvorn \& Chen, 2011; Rockstuhl, Seiler, Ang, Dyne, \& Annen, 2011).

\section{Cultural Definitions.}

Universalism-Particularism. Universalism refers to rules, laws, equity, and contracts that should be applied in any situation regardless of the relationship. Particularism, a dimension where China scores among the highest according to Trompenaars and Hampden-Turner (1997), refers to rewards being allocated based on relationship and personality desirability (Chiu, 1989). Reward allocation explains the prevalence of guanxi in Chinese culture - a system that involves prioritizing relationship, influence, and possible bribery to guide or control desired outcomes.

Individualism-Collectivism. A well-established, crosscultural, generalized divergence between Western and Eastern cultures where Western cultures tend to be individual-oriented and Eastern cultures are collectivist. This dimension tends to be more 
involved than just the generalized understanding of individualism versus collectivism in that collectivism involves the sense of one's obligation to the group, group identity, in-group/out-group dynamics, and trust, as noted by Trumpenaars and HampdenTurner. These considerations also impacted our study and teaching observation.

Affective-Neutral. Concerns how we communicate or express our feelings. Affective involves demonstrative behaviors, whereas neutral involves emotionally controlled or detached expressions.

Specific-Diffuse. These dimensions involve communication style, where specific means to be direct and diffuse is at the opposite end of that continuum.

Western cultures are affective/specific "where people attempt to find immediate outlets for their feelings, the mass of information is expressed very explicitly, and problems are expected to be directly and openly dealt with in an objective fashion" ( $p$. 10). Conversely, in Asian neutral/diffuse cultures: people tend not to telegraph their feelings but keep them carefully controlled and subdued, and very little information is explicitly communicated. In these cultures, the problem is approached diffusely, and group harmony may often be prioritized at the expense of reaching a final agreement (Hall, 1976; Hoftede, 2003; Trompenaars \& Hampden-Turner, 1997). Our participants cited many instances, and we observed multiple situations where this cultural interplay existed counter to our Western-centered assumptions and pedagogical expectations.

Achievement-Ascription. This dimension in the Trompenars and Hampden-Turner typology describes the status one attains due to what one has done instead of who one is. Western cultures are characterized by leadership that is results-based with managing tasks, goals, and decision-making processes that involve personal influence based on referent or expertise power. Conversely, Asian cultures focus on the maintenance of good relationships rather than the management of work. Therefore, leadership is a function of one's personality wherein one behaves in ways that demonstrate virtue and morality. The leader also ensures that team members behave similarly. Emphasis is on interpersonal considerations rather than tasks and objectives (Maccoby, 1994; Gunning, 1997).

Attitudes towards Time. Monochromic time (M-time) versus Polychromic time (P-time). Monochromic time cultures rely on the clock and are dominated by schedules, appointments, and segments of time passage. Polychromic time cultures give sway to socio-emotional activities and interactions between people. These cultures build group trust before commencing a task. Trompenaars and HampdenTurner (1997) only treat six of the seven dimensions, sufficient for this study to delineate cross-cultural distinctions.

Conclusion. A review of the literature indicates sufficient rationale for a study of this nature. While most of the extant literature lays focus on the economic and political implications of the international presence of United States higher education, there is a gap in contributions aiming to address the cultural divide relative to the practical application of theory, misaligned expectations between educators and students, and the cultural appropriateness of the curriculum. The current study seeks to fill that gap and present empirical evidence to understand these phenomena better.

\section{Conceptual Framework}

Here, we present a case where student expectations and cultural identities may not align with a Western leadership studies class's content and pedagogy. This study investigates the difficulty in applicability that may result. 


\section{Research Questions}

The following research questions guided the current study:

1. To what extent do students perceive curriculum applicability in a Western-based leadership education program to experiences outside the classroom?

2. To what extent are Chinese students' in-class experiences and competencies aligned with the preconceptions of a Western (United States) Leadership Education curriculum?

\section{Methodology}

Explanatory Sequential Design. We chose a mixedmethod design because of the project's complexities and interrelated issues in exploring philosophical and cultural approaches to present more robust and comprehensive data (Kingston, Sammons, Day, \& Regan, 2011). An explanatory sequential mixed methods design allows the researcher to use a qualitative phase of data collection to elaborate or explain findings by building on an initial quantitative phase of data collection (Ivankova, Creswell, \& Stick, 2006). Figure 1 illustrates the phases of this research project.

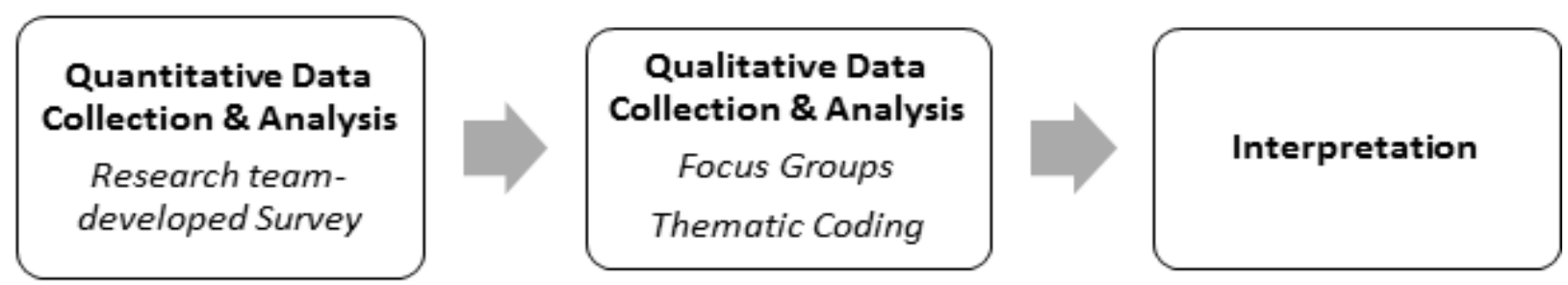

Figure 1. The order of progression and components of the explanatory sequential design (Creswell \& Plano Clark, 2011). 
Phase One Data Collection. We distributed a researcher-developed survey instrument to currently enrolled students of leadership studies curriculum at a private university in Mainland China. The survey was informed by a review of the literature and distributed using the online survey software, Survey Monkey. The use of software-generated emails and Q.R. codes facilitated participant access to the instrument.

Survey Instrument. The research team-developed survey instrument included questions that sought to highlight students' expectations and perceptions. Because it is of paramount importance that participants fully understand the survey questions, we translated each question-- and possible responses-- and presented them in both English and Chinese. We formatted nearly all of the questions as multiple choice -- allowing a single unique response, or multiple responses, to make survey completion easier and quicker for participants (Dillman, Smyth, \& Christian, 2014). We used drop-down menus to design questions for participants to choose from a limited set of responses.

Participant Sample. We distributed the survey instrument to students enrolled during the spring semester of 2018 in leadership courses with a Western (United States) curriculum. The students range in class standing from sophomores to seniors and majority male (55.75\%) distribution. Sample sizes were $N=467$ in phase one and $N=30$ in phase two.

The participants were Chinese students enrolled at a Chinese university taking classes from a U.S. university in a partnership with the Chinese university. The Chinese university wanted to offer Chinese students Western courses and majors. While some students earned single degrees from the U.S. university, many others earned dual degrees: one from the Chinese university and the other from the U.S. university. All Western courses were taught in English and were required. The students were in various leadership courses ranging from sophomore through junior year. The Chinese partner institution did not teach leadership or have any leadership-oriented classes. All students had to achieve a minimum English proficiency level to take Western classes, although skill-level ranged from low to high.

Phase Two Data Collection. The second phase of the current study included qualitative focus group interviews. Merriam (2009) endorses qualitative inquiry to uncover meaning in a particular experience or phenomena. We asked participants to reflect on their personal experiences and expectations during the semi-structured interviews and offer perceptions regarding Western leadership education's utility. The results informed specific questions and prompts for the focus group interview protocol of the quantitative survey. Participants for the focus groups were volunteers who participated in the phase one survey and had indicated availability and interest in speaking further about their leadership education experience.

Data Analysis. In addition to applying descriptive statistics to ascertain means and frequencies, inferential analyses, such as scatter plots and correlations, provided insight into the relationships between the applicability of leadership concepts, student experience, and expectations. Data collected during the initial quantitative survey informed the development of the qualitative interview protocol. Following the implementation of both research phases, findings were again integrated, or "mixed," in the data analysis stage. Coding and analyzing qualitative data reveal common themes across participant experiences, competencies, and demographics.

\section{Researcher Positionality Statements}

Dr. Brendon Fox. I come from a military family. The military stationed us on various bases nationally and 
abroad. As a result, I developed an appreciation for other cultures due to my immersion in them.

After earning my Ph.D. in 2015 at a U.S. university, I accepted the opportunity to teach leadership in China. The cultural shift to China was a much more difficult transition than I anticipated. Most Chinese people in the Mainland do not speak English, and I found that many of the conveniences and freedom I had in the U.S. were no longer available in the accommodations we had at our partner universities. After teaching Chinese students for approximately one year, I noticed stark differences between inclassroom participation, performance on tests, and comprehension/synthesis of our material. Most Chinese students did not engage freely in classroom discussion, and they routinely performed poorly on exams.

Chinese students regularly engage in what we think of as cheating. I learned from them that they consider this "helping," and it does not carry the same stigma as Western-centered higher education. What we call cheating is tolerated in Chinese culture, and to some degree, expected. Parents and students routinely tried to pay off or bribe instructors as a predictable practice to establish guanxi. While many U.S. instructors in Western-oriented classes faced frustration from the rift in student/teacher expectations and performance, there were several academic standouts. It is in this context that we based our investigation.

Dr. Jeff Bourgeois. Having lived and worked as an educator in several countries, I have always found it intriguing to note the cultural differences presented in-and-out of the classroom. The motivations, expectations, interactions, and engagement levels of people from different backgrounds create the potential for misunderstandings and misgivings and provide opportunities for broader perspectives. Following the successful completion of a Ph.D. program in the United States, I began teaching leadership for a small, MidWestern public university at the international partnership in mainland China.
Quickly Ilearned that, while the language of instruction was English, cultural differences would shape the connections I would make with the students and the course material I include in my classes. Identifying as a white, Western-educated male, I have come to understand that my social and cultural identities shape my personal and professional perspectives. My goal for this project was to deconstruct some of the classroom's cultural interactions, to understand students' experiences better, and gain insight into how their cultural identities guide them in understanding and applying the course material.

\section{Results}

An initial analysis of the data confirms a disconnection from our Chinese students' expectations and Western leadership curriculum utility. In addition to language differences, the phase one data collection revealed moderate student challenges with the cultural shifts in concepts such as collaboration, power distance, communication, and values regarding time and definitions of success.

Overwhelmingly, students recognized that leadership courses' utility focused on practical behaviors and strategies over courses that leaned on theory. During several focus group conversations, multiple students could cite out-of-the-classroom situations in which they implemented the concepts acquired in their leadership curriculum. While considering nuanced cultural differences, specific concepts included communication skills, group dynamics, and collaboration.

Implications of the Study. This study attempted to discern the degree to which students in Mainland China synthesize leadership theory and practice using current pedagogical methods. As stated earlier, our experiences seemed to reflect a relative lack of knowledge transference that rose to a satisfactory level. We began to wonder whether Western teaching 
practices led to an "elitist" educational approach or "neocolonialism" as described by Nguyen et al. (2009), where Western interests and values are promulgated above the host country as a possible explanation. Instead, this study verifies through quantitative and qualitative data, our experience as embedded teachers. It is consistent with some aspects of Communicative Language Teaching (CLT) and the Chinese Culture of Learning ( $\mathrm{Hu}, 2002)$.

CLT is the attempt by the People's Republic of China (PRC) to implant "communication-oriented English textbooks, developing skill-oriented examinations, and upgrading teachers' knowledge of new languagelearning theories and pedagogies" (p. 94). Hu (2002) notes that CLT has not received widespread support; traditional approaches are still dominant. Reports from the participants in this study confirm conventional Chinese learning methods through memorization, discouraging critical thinking, or engaging in dialogue with their Chinese teachers from primary through secondary education. Our participants unanimously recount the ongoing differences between their English-based classes and their Chinese-instructed classes.

The culturally dichotomous approach to teaching directly impacts student-teacher expectations, behaviors, and synthesis. The student must use a wholly antithetically-oriented set of skills to demonstrate success. For example, as $\mathrm{Hu}$ (2002) posited, Chinese learning consists of reception, repetition, reproduction, memorization, and mastery. These are the main competencies cited by our respondents in Phase II of our study when comparing Chinese classes to their leadership classes. In contrast, success in the Western context holds that students are encouraged to ask questions, engage in discussion, use critical and creative thinking to solve problems and arrive at a solution. This conflict in pedagogy ill-prepares students who enroll in leadership studies curricula because they have been taught and conditioned to think and behave as followers. As one respondent shared, "We will not read the book unless you tell us to." Another shared, "I can understand your words, but maybe sometimes
I can't understand your meaning because my critical thinking is bad."

\section{Summation of the Results.}

Phase I. In the quantitative phase, the research team assembled ten questions asking respondents about their leadership experiences to determine their assessment of leadership concepts' applicability in their lives. There were three demographic questions, followed by five self-evaluative questions about English proficiency. The responses informed the focus group questions used in Phase II.

$88.44 \%$ of respondents said that the concepts discussed in leadership courses remind them of situations they have experienced in their personal lives sometimes or most of the time. $42.64 \%$ said that they could relate to the theories and concepts presented in leadership class an average amount, followed by $38.31 \%$ who said they could relate "pretty well." A majority of respondents (58.75\%) said they are "a little familiar" with examples used in the textbook to explain different theories and concepts. The second-lowest percentage $(9.94 \%)$ responded that they are very familiar. $40.39 \%$ said that their instructors give them reading assignments that are only sometimes specifically about China. That was the largest number. The "sometimes" response was mirrored by students who said that their instructors give homework assignments or projects specifically about China (38.70\%). Students felt that the utility (usefulness) of leadership courses is somewhat to very useful compared to what they learn in other classes (90.63\%). $56.62 \%$ of students said that they use the lessons learned in leadership class outside of class, followed by $24.30 \%$ who said they use those lessons most of the time. Most respondents (32.32\%) said that they enrolled in the leadership major because they were interested. Finally, most (70.72\%) said they learn the most from movies or videos to synthesize the material. 
Phase II. The study's qualitative phase finds themes that emerged from the quantitative data collected and the semi-structured focus group interviews. Although much of the data affirms the dimensions mentioned in the Trompenaars and Hampden-Turner study, we observed and documented divergent notions of the saliency of collectivism and the effectiveness of the affective-neutral/specific-diffuse communication typologies. We also find a departure from the "Confucian thinking" offered by Hu (2002) concerning traditional Chinese conceptions of education as exhibited by our students' responses and behavior. Confucian thinking implies a deep reverence for education as a means of turning an ordinary person into a superior one and a weak nation into a strong one (pp. 96-97).

\section{Discussion of the Results}

Emergent Themes. In all, we had six focus groups that covered students in their sophomore through their senior year of college. This range contributed to the variance in responses and student perceptions of leadership study and its utility for application. To achieve this, we interviewed three classes each. The emergent themes are reflective of recurring focus group discussions. Although some surprises surfaced, much of what the respondents shared were consistent with our observed teaching experiences.

Theme 1. The Utility of Leadership Concepts. The saliency of leadership education closely aligns with the level of progression through the coursework. Focus groups consisting of lower classmen could point to very few examples of when leadership played a role in their lives. There were a couple of exceptions to this. One student enrolled in his first leadership class said that he uses the concepts with his girlfriend and in team situations while playing basketball. Two others said that they use or recognize leadership concepts in current non-student teams. One lower classman noted that he now recognized leadership concepts that a manager at a previous job had used.

Upper-level students were able to draw upon their multiple experiences in and out of class. One was particularly exuberant about using concepts to help her in her volunteer activities in recruiting new members. Another recalled his involvement with an AIDS initiative in Henan Province and how he and his team applied leadership to help get needed medicine to patients. Nearly all upperclassmen reported improved communication and management of teams and projects.

Theme 2. Student Commitment/ Preparedness. Our findings and experience are contrary to the assumptions of traditional Confucian education concepts forwarded by $\mathrm{Hu}$ (2002), which details the deep reverence for education as a serious undertaking (deep commitment and painstaking effort), the acquisition of knowledge through written texts, and how effort, determination, perseverance, and patience are valued student behaviors (pp. 96-98). Nearly all students said they do not or sometimes engaged in the assigned reading to prepare for class. A few said that they might read the material after class to increase their understanding. Still, reading was a low priority for many reasons, including lack of time due to workload, lack of comprehension, or lack of interest. Put by one respondent, "We have no time to read."

We find that students approach learning as a transactional endeavor. A response in one focus group from a student said, "I read it one time because I had heard you 
were angry that another class didn't read." We found that students would only read when we quizzed them or if we deducted points for non-compliance. This lack of compliance was universal across class or English skill levels.

Students revealed that their critical thinking abilities were low. Many cited the stark differences between Chinese and Western classes. In their Chinese courses, they are not allowed or encouraged to engage in questions or discussions with their teachers. Hu (2002) asserts that the teacher is the transmitter of knowledge and the student as the receiver. The teacher is in a hierarchical relationship with the student and has "all of the correct answers at all times" in this directive role (p. 99). Finally, one student revealed that even though they are commonly in teams at the college level, they were more accustomed to working individually for much of their primary and secondary educational experience. This cross-cultural tension was the source of students being ill-prepared for successful outcomes in our leadership classes.

Theme 3. Student Outcomes. Our findings and experience is at odds with Trompenaars and Hampden-Turner (1997) dimension of Individualism-Collectivism. Respondents found collectivist approaches to Western pedagogy problematic. Many high-functioning students find themselves obligated to help their classmates who do not understand the lecture or the reading. One respondent said, "Yes, every time they ask me 'What did the teacher say?"' Another reported,

When I am the leader of a team, I always support them and to be democratic. And maybe in some classes, I support them, and it made me tired, but after I studied leadership, I learned to delegate-delegate tasks to them to help me finish the task.

She went on, "When I am a sophomore student, I am a leader of three teams, so I was tired, which made me upset sometimes. So I needed to delegate to others sometimes to help me finish the task." These findings are consistent with what Fox (2015) posits as "Cultural Reframing." In his study of mentoring experiences, he asserts:

Cultural reframing occurs when the existing cultural norms, values, and expectations of the mentee is reoriented toward a divergent cultural perspective. The new cultural perspective enables the mentee to be open to and practice new behaviors suitable for success in the new environment ( $p$ 113).

Cultural reframing explains the crosscultural tension and the observed and reported behavioral difference in widelyheld Asian collectivism. Our respondents generally acknowledged the anxiety they experienced from traditional Asian group harmony notions in the team formation process. They prefer that the teacher relieve them of possible social alienation of not wanting to bend to those norms.

Nearly all students recounted several instances of improved communication, relationships, and emotional intelligence, which suggests satisfaction with learning objectives and a desire to employ leadership education once synthesized. The comments from one focus group where as follows:

In a relationship, for example, with my girlfriend, if we argue, first I will take care of her feelings. I think about what she thinks, why she thinks that and where we are different and cooperate to solve the problem. But we must cooperate the find where we are different. 
Another student in the same group said:

Yes. About my roommate relationships. Because in China, we have six people in one [residence hall] room. Sometimes, we don't want to see too much of each other. But now we think we need to speak clearly and pay attention to each other's feelings.

In a different group, one student said:

I think in basketball, you need to communicate with your teammates, and you remember we talked about Michael Jordan in the first class? His leadership can influence people. I used to be very selfish. I just wanted to get to the goal. I would be upset and angry if my teammates threw the ball away. And now, I would encourage them if they shoot an airball, it's fine.

Another student in the same group said:

I have a Microsoft Office class where we teach students for free. The class consists of 30 people. We study every night. I took over the leadership in the class. I was taught by an older student how to deal with problems from teachers. The lessons I learned from the leadership class teaches us how to deal with people.

In terms of putting leadership education into practice, a student from a different group shared:

Yeah, for me, when I really do that, and at that moment, I can really realize that meaning. But when I go to class, I can understand, but I can't use it. So you mean when we talk about recruitment, I remember that word. But when I really doing recruitment for World Academy, I even reviewed your PPT, and read the book and get some ideas to put into action. But when I put it into action, I totally understand. And in your class you let us be the teacher to teach the classmates, I think that's a good activity, but most students don't understand that they just read the sentence and just translate, but I understand your purpose.

These examples demonstrate the saliency of leadership education for students in Mainland China in a fundamental way and further demonstrates their transcendent philosophical grasp of leadership in practice.

A final student-a graduating senior, discussed how his leadership education had equipped him with additional options when engaging in leadership situations. While he may not always employ specific strategies or concepts, this student conveyed an appreciation for having "more tools" to select for problemsolving or other circumstances. This growth reflects students' critical thinking ability in prescribing Western concepts in concert with Chinese culture's contextual implications. In other words, although students did not always utilize leadership lessons to do different things, they were equipped to use the acquired knowledge to do things differently.

Theme 4. Pedagogical Practice. This theme emerged because of incongruences between the $\mathrm{CHC}$ in Mainland China and Western approaches to education. Respondents gave numerous examples of this mismatch. They talked about how creative thinking, critical thinking, and dialogue are discouraged. They cited the emphasis placed on memorization without understanding, which is the Confucian tenant of knowledge accumulation ( $\mathrm{Hu}$, 2002). "Yeah, and different from Chinese education. In Chinese education, we just study, study in a book. Activities would help me grow."

The Chinese textbooks have a lot of definitions, so you can memorize them. Not like an English textbook, you read a story, 
and you understand what they are talking about. Chinese students like to memorize things. You give a test, and they memorize everything. They don't understand the words. They just memorize everything.

Another respondent characterized it as follows:

The homework helps us understand some words' meanings. I find that if I don't understand in class, I will go to the textbook, and I will find the answer, and it will help me understand the meaning. In Chinese classes, we always do much homework, and maybe we don't know the true meaning but just know the answer. We don't understand what they say, but I know to write down this, it's right.

These student practices illuminate why they do not ask questions in class: it is unnecessary to understand it immediately. They may understand later, once the knowledge is needed, according to the Confucian view. This dissonance in preparation and performance expectation leads to the students being wholly ill-suited for success in a Western classroom environment. Failure on exams is a predictable outcome because of their comfort with the lack of synthesis of material. This outcome is further compounded by the lack of expected behaviors like reading due to time or the daunting language barrier.

Students reported appreciation for the practice of teachers selecting their teams for them to rid themselves of friends who depended on them too heavily. One respondent said, "There are always some students who want to follow you. You can't refuse them because I can help them do the work. And I can't refuse them." Another said, "Yeah, after you finish class, I explain in Chinese what they need to do. Sometimes I think, 'Why do I explain in class and then, two days later you ask me again?"'

There was a concern for social loafing among their lower-performing peers, and they felt overburdened in having to compensate. Some students offered recommendations for how we should assemble teams. "I think you should choose A, B, C, D, and choose the groups that way." This suggestion refers to A-level, B-level, and so on.

High functioning students nearly unanimously point to the desire to have practice or activities that reinforce or replace the lecture. They also point to movies or videos as providing the context for understanding leadership concepts. We believe that this informs a pedagogical shift in marrying Western and Chinese traditional approaches.

Significance of the Study. The study's significance is that it provides context to the pedagogical approach in teaching leadership to Mainland Chinese students. It provides an ethnographic description of the mismatches between Western pedagogical methods that involve Cooperative Learning $(\mathrm{CL})$ and Confucian Heritage Cultures $(\mathrm{CHC})$ along the seven dimensions: Universalism-Particularism, Individualism- Collectivism, Neutral-Emotional, Specific-Diffuse, Achievement-Ascription, Attitude to times, and Attitude to the environment (Trompenaars \& Hampden-Turner, 1997). The study addresses the dearth of systematic research in the Asian context (Nguyen et al., 2009). These dimensions explain the polarity in situational student-teacher expectations and behavior.

\section{Implications for Teaching Leadership}

Our study reveals gaps in preparation, practice, 
student-teacher expectation, and outcomes. Since there are glaring extant cultural rifts in all of these areas, there is a strict and looming dichotomy in pedagogy that renders current teaching practices virtually ineffective relative to the conferring institution's desired outcomes and expectations. We recommend modifying current pedagogy that transcends memorization and lecture but aligns leadership programs with actual business/ management practice in real-world settings.

For students in Mainland China, we recommend partnering with organizations willing to provide cooperative education opportunities or internships to university students to apply the practice. For example, Fort Hays State University has three classes that provide opportunities for students. Fieldwork in Leadership Studies provides students with opportunities to improve organizations or engage in an experiential service project. Introduction to Leadership Behaviors has a final project that is a strategic plan for an existing organization. Principles of Civic Leadership studies six practices that high impact non-profits use. Students could apply these practices to a local community organization. This type of action-oriented learning would facilitate student comprehension and improve student-teacher outcomes, expectations, and overcome the difficulties that exist due to lack of language proficiency. One of the high-functioning students wrote:

My favorite Leadership class that I have taken is Field Work in Leadership Studies. Because we can apply knowledge to practice, also because of the value I personally receive from this class, we can build our teamwork on Sustainable Development Goals and raise awareness for all of these social issues to act as an influential leader to help communities make real changes. We have a lot to bring to the world!

\section{Limitations}

A recognized limitation was our questions requiring self-evaluation of English proficiency. Most students reported themselves as "average" or "a little below average." These evaluations do not account for modesty or lack of self-awareness. There should be an instrument to objectively evaluate and scale English competency related to this and other studies. An indication of this questioning mode's inaccuracy is the statistical data and what most students related during the interviews. Many said that most of their peers do not understand the teachers or the reading. The selected coding method only produces themes from the values aspect of the collected data. Values coding explores a participant's beliefs, attitudes, and values (Saldana, 2013). Other forms of coding, like process coding, would examine the actions of an observable activity.

Finally, although we surmise that the sample was representative of students' values in Westerncentered leadership curriculum at a private, former tier-three university in Henan Province, a limitation is that the responses may not be representative of students at more prestigious tier-one, public schools. Those students may have a deeper understanding or be more capable of synthesizing Western-based constructs, especially if they have higher English proficiency.

\section{Recommendations for Further Study}

An exciting avenue for future study would be a longitudinal study of the utility of leadership education post-graduation. That study would provide further context and continuity toward understanding leadership concepts before program involvement, the development of leadership fluency as a student, and what happens after successful completion. The study could focus on graduates working for Chinese organizations in Mainland China and contrast them with graduates studying or working abroad.

As mentioned above, we recommend larger, tier-one public universities in China conduct future research to study the effects of students who have experienced higher levels of academic success. That study would 
validate the findings in this study or dispel the notion that students with higher comprehension of Western approaches and English proficiency may be more suited for leadership study and participation in a globally oriented workforce. 


\section{References}

Altbach, P. G. (2003). Academic colonialism: Accreditation of foreign universities. International Higher Education, 5-7.

Altbach, P. G., \& Knight, J. (2007). The internationalization of higher education: Motivations and realities. Journal of Studies in International Education, 11(3-4): 290-305.

Blanco-Ramirez, G. (2013). Quality by association across north-south divides: United States accreditation of Mexican institutions of higher education. The University of Massachusetts. Retrieved from http:// scholarworks.umass.edu/cgi/viewcontent.cgi?article=1841\&context=open_access_dissertations.

Bourgeois, J. (2017). Neither here nor there: Transformational leadership and cultural intelligence in presidents of U.S.-accredited universities located in foreign countries. [Unpublished doctoral dissertation]. The University of San Diego.

Chestnut, B. (2017). The 9 types of leadership: mastering the art of people in the 21st century workplace. Simon and Schuster.

Chiu, C. Y. (1989). Reward allocation among Chinese high school students in Hong Kong. The Journal of social psychology, 129(6), 751-757.

Ciulla, J. B. (Ed.). (2014). Ethics, the heart of leadership. ABC-CLIO.

Conger, J. A., \& Kanungo, R. N. (1998). Charismatic leadership in organizations. Thousand Oaks, CA. Sage Publications.

Covey, S. R. (1991). The seven habits of highly effective people. National medical-legal journal, 2(2), 8.

Crawford, C. B., Brungardt, C. L., \& Maughan, M. R. C. (2005). Understanding leadership. Hoboken, NJ. Wiley \& Sons.

Creswell, J. W., \& Plano Clark, V. L. (2011). Designing and conducting mixed methods research (2 ${ }^{\text {nd }}$ ed.). Thousand Oaks, CA: Sage Publications.

Crossley, M., \& Tikly, L. (2004). Postcolonial perspectives and comparative and international research in education: A critical introduction. Comparative education, 40(2), 147-156.

Crowne, K. A. (2008). What leads to cultural intelligence? Business Horizons, 51(5), 391-399.

Dillman, D. A., Smyth, J. D., \& Christian, L. M. (2014). Internet, phone, mail, and mixed-mode surveys: The tailored design method ( $4^{\text {th }}$ ed.). Hoboken, NJ: Wiley and Sons.

Equity Alliance (2011). The equity alliance at ASU. Retrieved from http://www.equityallianceatasu.org/

Feuchtwang, S. (2016). Religions in the modern world: Traditions and transformations. New York: Routledge.

Fiedler, F. E. (1967). A theory of leadership effectiveness. McGraw-Hill.

Fox, B. C. (2015). Cultivating a passion for excellence in African American and Latino college males: Mentor experiences in multitheoretical organizational ethnography. [Unpublished doctoral dissertation]. Capella University. 
French, J. R., Raven, B., \& Cartwright, D. (1959). The bases of social power. Classics of organization theory, 7, 311-320.

Gardner, J. (1993). On leadership. New York, NY: Simon and Schuster.

Goleman, D. (2005). Emotional intelligence. New York, NY: Bantam.

Greenleaf, R. (1977). Servant leadership. New York, NY: Paulist Books.

Gunning, J. P. (1997). Individual wills first - the real success behind the Asian tigers. Retrieved from http:// www.jyanet.com/cap/0613fe0.htm.

Hall, E. T. (1976). Beyond culture. New York, NY: Doubleday.

Hersey, P., \& Blanchard, K. H. (1969). Life cycle theory of leadership. Training \& Development Journal.

Hofstede, G. (2003). Cultures and organization-software of the minds. Profile Books Ltd.

Homans, G. C. (1958). Social behavior as exchange. American Journal of Sociology, 63(6), 597-606.

House, R. J. (1971). A path-goal theory of leader effectiveness. Administrative science quarterly, 321-339.

House, R. J. (1977). A theory of charismatic leadership. Leadership: The Cutting Edge. Southern Illinois University Press.

Hu, G. (2002). Potential cultural resistance to pedagogical imports: The case of communicative language teaching in China. Language Culture and Curriculum, 15(2), 93-105.

Ivankova, N. V, Creswell, J. W., \& Stick, S. L. (2006). Using mixed-methods sequential explanatory design: From theory to practice. Field Methods, 18(1): 3-20.

Javidan, M., House, R. J., \& Dorfman, P. W. (2004). A non-technical summary of GLOBE findings.pdf. Culture, Leadership, and Organizations: The GLOBE Study of 62 Societies: 29-48. Sage.

Kincheloe, Joe (2008). Critical pedagogy primer. Bern, Switzerland: Peter Lang.

Kingston, A., Sammons, P., Day, C., \& Regan, E. (2011). Stories and statistics: Describing a mixed-methods study of effective classroom practice. Journal of Mixed Methods Research 2, 5(2): 103-125.

Kwak, D. J., Kato, M., \& Hung, R. (2016). The Confucian concept of learning revisited for East Asian humanistic pedagogies. London, England: Routledge.

Lane, J. E., \& Kinser, K. (2013). Five models of international branch campus ownership. International Higher Education, 70(70): 9-11.

Lewin, K., Lippitt, R., \& White, R. K. (1939). Patterns of aggressive behavior in experimentally created "social climates." The Journal of social psychology, 10(2), 269-299.

Lovvorn, A. S., \& Chen, J.-S. (2011). Developing a global mindset: The relationship between an international assignment and cultural intelligence, 2(9), 275-283.

Maccoby, M. (1994). Creating quality cultures in the East and West. Research Technology Management 37(1): 57-59. 
McGregor, D. (1960). Theory X and theory Y. Organization theory, 358, 374.

Merriam, S. B. (2009). Qualitative research: A guide to design and implementation (2 ${ }^{\text {nd }}$ ed). New York, NY: JosseyBass.

Moulakis, A. (2011). What the U.S. government can't do abroad, colleges can. The Chronicle of Higher Education. Retrieved from https://doi.org/10.1017/CBO9781107415324.004.

Nguyen, P. M., Elliott, J. G., Terlouw, C., \& Pilot, A. (2009). Neocolonialism in education: Cooperative learning in an Asian context. Comparative Education, 45(1): 109-130.

Pavoncello, F. (2015). The Globalization of education. Longitude. 151: 112-115.

Potts, J. D. (2001). The ethical difference: Why leaders are more than managers. Longmont, CO: Rocky Mountain Press.

Rockstuhl, T., Seiler, S., Ang, S., Dyne, L. Van, \& Annen, H. (2011). Beyond general intelligence (I.Q.) and emotional intelligence (E.Q.): The role of cultural intelligence

(C.Q.) on cross-border leadership effectiveness in a globalized world. Journal of Social Issues, 67(4), 825-840.

Rost, J. C. (1995). Leaders and followers are the people in this relationship. The leader's companion: Insights on leadership through the ages. New York, NY: Free Press.

Saldana, J. (2013). The coding manual for qualitative researchers. Thousand Oaks, CA: Sage.

Seeskin, K. (1987). Dialogue and discovery: A study in the Socratic method. Albany, NY: SUNY Press.

Spring, J. (2008). Globalization of education: An introduction. London, England: Routledge.

Stogdill, R. M. (1948). Personal factors associated with leadership: A survey of the literature Journal of Psychology, 25, 35-71.

Stogdill, R. M. (1974). Handbook of leadership. A survey of theory and research. New York: Free Press.

Tikly, L. (2004). Education and the new imperialism. Comparative Education, 40, 173-198

Trompenaars, A. \& Hampden-Turner, C. (1997). Riding the waves of culture ( $2^{\text {nd }}$ ed.). London, England: Nicholas Brealey Publishing

Turnbull, S. (2011). Worldly leadership: Challenging the hegemony of Western business education. Journal of Global Responsibility, 2(2), 170-187.

Wong, K. C. (2001). Chinese culture and leadership. International Journal of Leadership in Education, 4(4), 309-319. https://doi.org/10.1080/13603120110077990

Wu, X., \& Tarc, P. (2016). Translations and paradoxes of 'Western'pedagogy: perspectives of English language teachers in a Chinese college. L2 Journal, 8(4). 